\title{
Prótese intraocular de metilmetacrilato como alternativa à enucleação em equino: relato de caso
}

Gustavo dos Santos Rosa, Marilia Ferrari Marsiglia", Caio Nunes de Barros, Carolina Mura Ramos, Juliana de Moura Alonso, Micaella Gordon Gandolfi, Geórgia Nadalini Rodrigues, Cláudia Valéria Seullner Brandão, Ana Liz Garcia Alves, Carlos Alberto Hussni, Marcos Jun Watanabe, Celso Antônio Rodrigues

Faculdade de Medicina Veterinária e Zootecnia, Universidade Estadual Paulista (UNESP), São Paulo, SP, Brasil

*Autor correspondente

e-mail: mariliafmarsiglia@gmail.com

\section{Resumo}

Devido a sua posição proeminente na cabeça, os olhos são frequentemente acometidos por traumas que, em termos de severidade, podem variar desde uma lesão conjuntival leve até uma laceração severa da córnea com ruptura do bulbo ocular. Em casos de perfuração ocular, a intervenção cirúrgica é o tratamento de eleição, reestabelecendo as estruturas internas do olho. 0 diagnóstico clínico baseia-se na observação de irregularidades da superfície corneal, frequentemente acompanhadas por traves de fibrina, prolapso de íris, diminuição da pressão intraocular, câmara anterior rasa e extravasamento do humor aquoso, hipópio e hifema. De acordo com a causa da perfuração e a severidade da lesão, realiza-se o tratamento cirúrgico mais adequado. Como exemplos são citados enxertos conjuntivais, utilização de membrana amniotíca e, em casos de cegueira irreversível secundária ao descolamento de retina, glaucoma ou endofitalmite, enucleação ou o uso de próteses intraoculares. Quando a córnea encontra-se íntegra, a prótese intraocular pode ser utilizada, desde que haja tecido suficiente para a sutura em esclera, visando um aspecto estético melhor. 0 presente trabalho tem como objetivo relatar o descolamento de retina secundário à uveíte devido a corpo estranho intraocular, e a utilização de uma prótese intraocular de metilmetacrilato como alternativa à enucleação. Um equino, fêmea, da raça Mangalarga Marchador, de 7 anos, foi atendido no Hospital Veterinário da FMVZUNESP Botucatu após perfuração da córnea por fragmento de feno durante a alimentação no cocho, com 30 dias de evolução. 0 paciente apresentava blefaroespasmo, fotofobia, quemose e epífora, além de má acuidade visual. Após exame oftálmico, pôde-se observar edema corneal, hifema, hiperemia conjuntival moderada e um corpo estranho (CE), estrutura cilíndrica linear de aproximadamente 6 mm de comprimento, localizado na câmara anterior. Após insucesso na tentativa de tratamento conservativo com a administração de anti-inflamatório sistêmico (flunixin meglumine, $1 \mathrm{mg} / \mathrm{kg}$ ) e local (diclofenaco sódico 4-4h), antibiótico (Tobramicina 6-6h) e midriáticos, optou-se pelo procedimento cirúrgico para a excisão do CE. Mesmo após 
a excisão do CE e terapia pós-operatória intensiva, não houve retorno da visão ou diminuição dos sinais de inflamação devido à uveíte, causando dor severa. Optou-se, então, pelo emprego de uma prótese intraocular de metilmetacrilato (resina acrílica) devido ao resultado estético superior. Antes da cirurgia, o diâmetro da córnea foi mensurado (30 mm) e uma esfera de metilmetacrilato foi moldada e esterilizada. A técnica cirúrgica utilizada consistiu na evisceração de todo o conteúdo intraocular, com acesso pela superfície dorsal da esclera. Em seguida, a prótese foi introduzida pela incisão e a esclera foi suturada em padrão simples contínuo, utilizando fio de poliglactina 910 6-0. Em seguida, foi realizado um flap conjuntival sobre a sutura da esclera. A conduta pós-operatória com flunixin meglumine e ceftiofur IV foi suficiente para promover o conforto e evitar infecções. 0 animal recebeu alta cerca de 20 dias após a implantação da prótese, sem sinais clínicos de desconforto ocular. Lesões orbitais e oculares devem sempre ser consideradas emergências. A enucleação ocasiona deformidades faciais, característica muitas vezes desagradável ao proprietário. Para casos similares em que a aparência é um fator importante, a literatura recomenda a utilização de próteses de silicone. Entretanto, devido à natureza inerte do metilmetacrilato, a utilização de esferas pré-moldadas estéreis deste material não resultou em reações de caráter imunogênico. Em suma, o presente relato demonstrou que a biocompatibilidade do metilmetacrilato suporta sua utilização como matéria-prima para próteses em oftalmologia veterinária. A realização de cirurgias oftálmicas cosméticas utilizando próteses intraoculares estabelece excelente alternativa à enucleação, gerando resultados esteticamente mais adequados em equinos.

Palavras-chave: Oftalmologia. Uveíte. Cirurgia cosmética. 